\title{
Frontal fibrosing alopecia
}

INSERM

\section{Source}

INSERM. (1999). Orphanet: an online rare disease and orphan drug data base. Frontal fibrosing alopecia. ORPHA:254492

Frontal fibrosing alopecia (FFA) is a rare variant of lichen planopilaris (see this term) characterized by symmetrical, progressive, band-like anterior hair loss of the scalp. 